Review Paper

\title{
Nanotechnology for Alzheimer's disease detection and treatment
}

\author{
Amir Nazem ${ }^{1}$ and G.Ali Mansoori ${ }^{2,}$ *
}

1 College of Medicine, Mashhad University of Medical Sciences, Mashhad, Iran

2 Department of BioEngineering, University of Illinois at Chicago, Chicago, IL 60607-7052, USA

* Author to whom correspondence should be addressed; UIC, $851 \mathrm{~S}$. Morgan St. (M/C 063), Chicago, IL 60607-7052, USA. Voice: +1-312-996-5592; Fax: +1-312-996 5921; Email: mansoori@uic.edu

Received: 16 August 2011 / Accepted: 21 September 2011 / Published: 04 October 2011

\begin{abstract}
In this paper, we present the role of nanotechnology in the development and improvement of techniques for early diagnosis and effective treatment of Alzheimer's disease (AD). Since AD pathology is almost irreversible and present-day medications for $\mathrm{AD}$ only lower its associated symptoms, application of disease-modifying treatments could be successful only if $\mathrm{AD}$ early diagnosis is possible. The nanodiagnostic methods reported and compared in this paper include both of in vitro and in vivo nature. Of the in vitro approaches, the DNA-nanoparticle conjugates (bio-barcode assay), nanoparticle surface plasmon resonance, scanning tunneling microscopy, and two-photon Rayleigh spectroscopy are presented here. Of the in vivo methods, $\mu \mathrm{MRI}$ and optical imaging techniques are discussed here. The nanotreatment methods for AD are numerous. They are categorized in this report under neuroprotective methods from toxicity of amyloid- $\beta$ peptide (A $\beta)$ oligomers, oxidative stress of free radicals and nanocarriers for targeted drug delivery. The important agents for neuroprotection include nanogels, fullerene, nano-ceria, dendrimers, gold nanoparticles, and diamondoid derivatives. The major nanocarriers presented here include cholinesterase inhibitors nanocarriers, acetylcholine nanocarrier, metal chelator nanocarriers, (Iron chelators and copper chelators), curcuminoids nanocarrier, anti-oxidant nanocarriers, and gene nanocarriers. Considering that the $\mathrm{AD}$ is a multi-factorial disease with several pathogenetic mechanisms and pathways, a multifunctional nanotechnology approach will be needed to target its main molecular culprits. These molecular targets must include, but not limited to, $\mathrm{A} \beta$ oligomers, reactive oxygen species (ROS), excessive metal ions, tau phosphorylating kinases and cell cycle proteins.
\end{abstract}


Keywords: Alzheimer's disease; Amyloid; nanocarrier; nanodiagnostic; nanoparticle; nanotechnology; nanotreatment; neuroprotection; tau protein; gene therapy; disease-modifying treatments.

\section{Introduction:}

Alois Alzheimer defined "senile dementia" more than a century ago with a remarkable accuracy [1, 2]. It is now known as the Alzheimer's Disease (AD), and is the main cause of the dementia syndrome [3]. The incidence and prevalence of $\mathrm{AD}$ increase with age. Since the elderly population is growing worldwide, $\mathrm{AD}$ is quickly becoming one of the major universal healthcare problems [4]. Today, however, there are neither precise diagnostic approaches nor effective therapeutic agents available for Alzheimer's disease.

The degeneration of nervous tissue begins many years to even decades before the patient experiences any of Alzheimer's disease symptoms [5-7]. On the other hand, the currently available therapeutics for AD, only act to lower its symptoms [8]. Therefore, whether the disease is diagnosed early enough or not, the conventional medical approaches are incapable of complete cessation or reversal of the disease progress.

The uncovering potentials of nanotechnology have been opening new chapters in many aspects of our lives, specially diagnosis and treatment of human diseases [9-11]. Through nanotechnology, the controllable production of desired structures and devices with, at least, one dimension in nanoscale (1$100 \mathrm{~nm})$ is presently achievable $[12,13]$. Nanotechnology is advancing molecular detection, drug discovery, delivery and monitoring for a number of ever-challenging human diseases, including cancer and neurodegenerative disorders [10, 14-16].

The success of nanotechnology approaches towards diagnosis and treatment of AD presented in this paper, demonstrates the role of interdisciplinary research for the early diagnosis and possible cure for AD.

\section{Nanotechnology-Based Diagnosis of Alzheimer's Disease}

En route to very early diagnosis of a complex disease like AD we need to have an affordable, ultrasensitive and selective molecular detection method. The recently growing application of nanotechnology in molecular detection of biomarkers is promising for very early diagnosis of Alzheimer's disease. From a practical point of view, one may perform a molecular detection process either inside the body (in vivo) or on the samples derived from the body (in vitro). Nanotechnology may help us to achieve early diagnosis of AD by providing us with a highly potent signal transduction approach. Signal transduction refers to the process through which a biological signal (a biomarker) transforms to a recordable signal, and is amplified enough to be recorded. This potential application of nanotechnology in molecular diagnosis is mainly based on the special physical (optical, electrical or magnetic), chemical and biological characteristics of certain multifunctional nanoparticles (see Figure 1). In what follows we present and compare a number of methods, which have aimed to address this need. 
Figure 1- Different stages of a molecular diagnostic method. Stage 1(shown in Blue) is Signal detection at molecular scale. This stage determines the technical specificity of the molecular diagnostic tool. Stage 2 (shown in Green) is Signal transduction, through which the detected signal will become recordable. For this purpose, the signal must change into a recordable form which could appropriately be amplified. Diagnostic methods that are capable of making weak biological signals recordable are sensitive enough to detect those biomarkers. Stage 3 (shown in Orange) is Signal documentation. In this stage, the transformed and amplified signal is recorded, visualized and measured. This stage determines the quantifiability of the diagnostic tool.

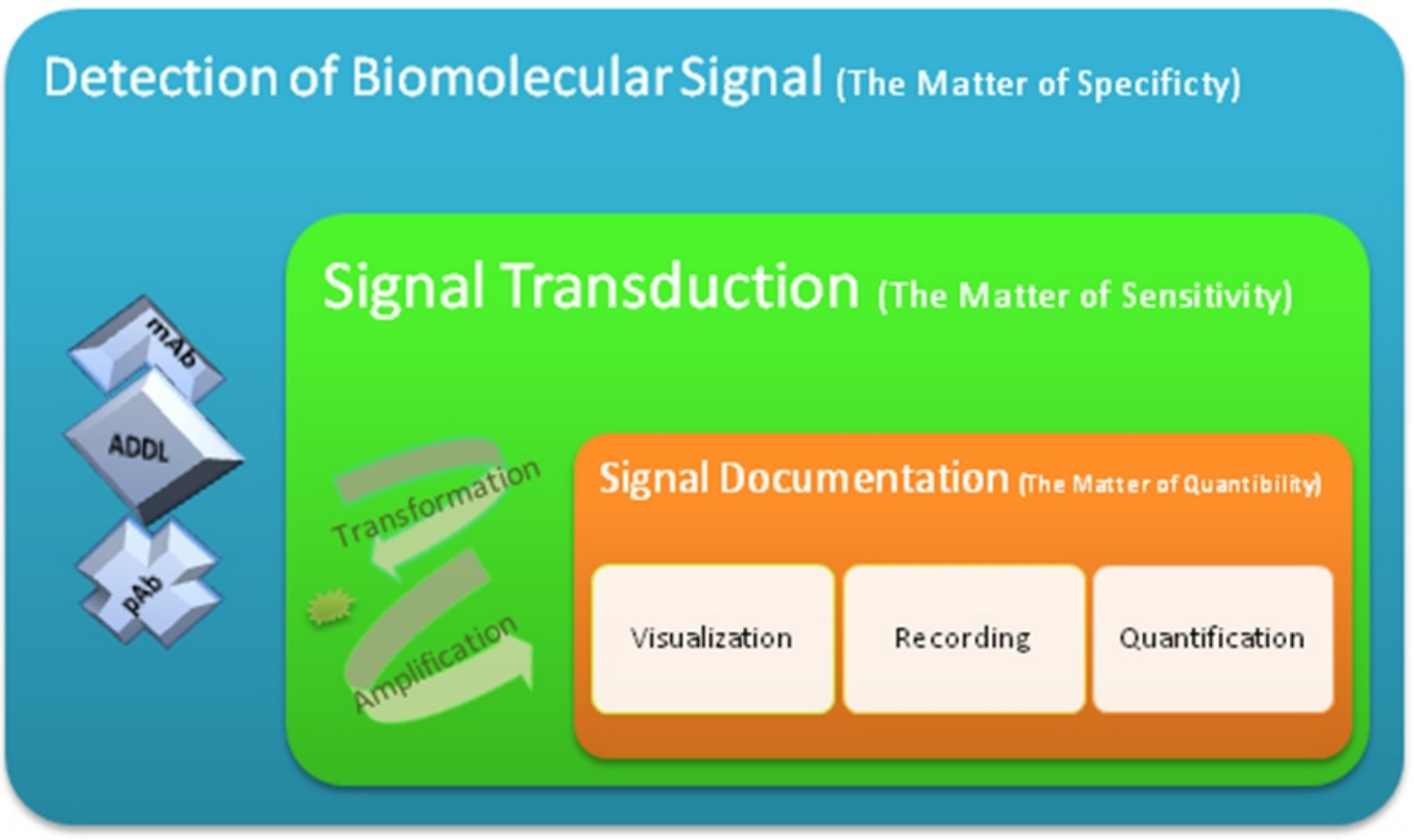

\subsection{Proposed In Vitro Nanodiagnostic Approaches}

\subsubsection{DNA-Nanoparticle Conjugates (Bio-Barcode Assay)}

DNA-Nanoparticle conjugates are capable of the attomolar scale detection of protein biomarkers [17]. Through a technique known as bio-barcode assay, ultra-low concentrations of protein biomarkers may be detected, owing to carrier gold nanoparticles that match the specific antibody of the target biomarker with hundreds of DNA barcodes. Therefore, a single molecule of biomarker may be traced by hundreds of DNA barcodes (a biological signal transformation), which could be additionally amplified by the polymerase chain reaction (PCR) technique [17]. Investigators of this project claimed a highly sensitive detection of amyloid $\beta$-derived diffusible ligand (ADDL) in cerebrospinal fluid (CSF) samples of AD patients through bio-barcode assay [17]. The reported results of this study show a significant difference between concentrations of ADDL in AD diagnosed subjects and in agematched healthy controls. The ADDL concentration medians of these two groups are reported as 1.7 $\mathrm{fM}$ and ca. $200 \mathrm{aM}$, respectively. This would prove a correlation between increased CSF concentrations of ADDL and affliction with AD. 


\subsubsection{Nanoparticle Surface Plasmon Resonance}

Recently a method for the detection of molecular biomarkers was examined for AD biomarkers [18] which is said to be ultra-sensitive and inexpensive. It is called the localized surface plasmon resonance (LSPR) nanosensor and it is based on singular optical properties of triangular silver nanoparticles (AgNPs). In this method, any changes in the nanoparticle external environment lead to a change in the refractive index of the surrounding magnetic field. This change subsequently changes the AgNPs' $\lambda$ max that could be detectable via spectroscopy. LSPR nanosensor is sensitive to different concentrations of target biomolecule (like ADDL) since the solution concentration directly changes the refractive index. Therefore, different wavelength shifts for different concentrations are detectable. Three applications for LSPR nanosensor are suggested which are: 1) To study oligomerization of the A $\beta$ in ultra-low concentrations, similar to concentrations of in vivo conditions, 2) To screen patients for $\mathrm{AD}$, and 3) To study the interactions of pharmaceutics with the target molecules in drug discovery.

\subsubsection{Scanning Tunneling Microscopy System}

Another recent development is a molecular detection system which was proposed based on electrical detection using a scanning tunneling microscope (STM) [19, 20]. The settings of this technique included immobilization of specific antibody fragments on gold (Au) substrate and $\mathrm{Au}$ nanoparticles (AuNP). After addition of the sample solution to the substrate, the antibody nanoparticle conjugates were added. The result was sandwich-type immune binding events that led to changes in tip-to-biosurface interval. These changes in the interval between the sample surface and the scanning tip of the STM affected the tunneling current (signal transformation). The tunneling current profile was then analyzed based on the frequency of the pulse-like peaks, which occurred every time the scanning tip passed over AuNPs. As it was reported, through this technique, an ultra-high sensitive detection of $\mathrm{A} \beta$ became possible at concentrations as low as $10 \mathrm{fg} / \mathrm{ml}[19,20]$.

\subsubsection{Two-Photon-Rayleigh Spectroscopy}

Recently, two-photon-Rayleigh scattering signal of AuNPs was examined as a transformed signal of an immunosensor for tau protein, one of AD biomarkers [21]. In this study, conjugates of AuNP with anti-tau antibody was used to detect tau proteins in a sample solution. The basis of biomarker signal transformation was the ensuing aggregation of AuNP-antibody conjugates after addition of tau protein. It is claimed that through this technique tau protein could be detected at concentrations as low as $1 \mathrm{pg} / \mathrm{ml}$ within 35 minutes. By using this technique, the investigators claimed to have introduced, for the first time, a fast, ultra-sensitive and specific nanosensor for detecting tau protein.

\subsection{Proposed In vivo Nanodiagnostic Approaches}

\subsubsection{Micro Magnetic Resonance Imaging ( $\mu M R I)$}

The usage of iron oxide nanoparticles as magnetic resonance imaging (MRI) contrast agents has been widely researched in the recent decades [22, 23]. Two groups of investigators have reported the application of monocrystalline iron oxide nanoparticles (MION) and ultra-small superparamagnetic 
iron oxide (USPIO) nanoparticles as MRI contrast agents for in vivo detection of amyloid peptide plaques in the brain of transgenic mouse model of $\mathrm{AD}[24,25]$. In both of these studies $\mathrm{A} \beta$ was conjugated to the nanoparticle in order to detect amyloid plaques $[23,24]$. This technique is claimed to be minimally invasive especially if the MRI enhancement agent (nanoparticles) is injected intravenously rather than intra-arterially [25]. However, since the amyloid plaques are targeted in the above-mentioned techniques, the technique could not be useful for very early diagnosis of $\mathrm{AD}$. This is because the amyloid plaque formation appears in later, more advanced, stages of the disease. Therefore, applications of this technique in the detection of AD may be limited to confirmation of established AD pathology in dementia patients, and monitoring therapeutic efficacy for those drugs that are aimed to reduce amyloid plaques.

\subsubsection{Optical Imaging}

Another recently growing approach for in vivo detection of molecular biomarkers is optical imaging through special near-infrared (NIR) fluorescent contrast agents [26]. Due to the long wavelength, the scattered light from these contrast agents could penetrate through biological tissues. The common requirements for a molecular diagnostic probe for $\mathrm{AD}$ include the ability to cross the $\mathrm{BBB}$ and specifically target an $\mathrm{AD}$ related biomarker (e.g. $\mathrm{A} \beta$ ). In addition to those, fluorescent contrast agents should have an appropriate absorption and emission wavelength interval (600-800 $\mathrm{nm}$ ) and a strong rigidification [26]. Rigidification refers to a phenomenon through which the fluorescent molecule undergoes a significant conformational restriction upon binding with a molecular target. Such conformational restriction decreases the non-radiative decay rate (and therefore increases the quantum yield) by reducing the rotational and vibrational processes that couple the ground and excited state [27]. The practical result of this phenomenon is the substantial imaging contrast between bounded and unbounded fluorescent markers [26].

Nesterov et al. proposed a NIR Alzheimer's dye known as NIAD-4 with the chemical formula [[5'-(4-Hydroxyphenyl)[2,2'-bithiophen]-5-yl]methylene]-propanedinitrile, for in vivo molecular detection of $\mathrm{A} \beta$.

Figure 2 - NIAD-4 [[5'-(4-Hydroxyphenyl)[2,2'-bithiophen]-5-yl]methylene]-propanedinitrile.

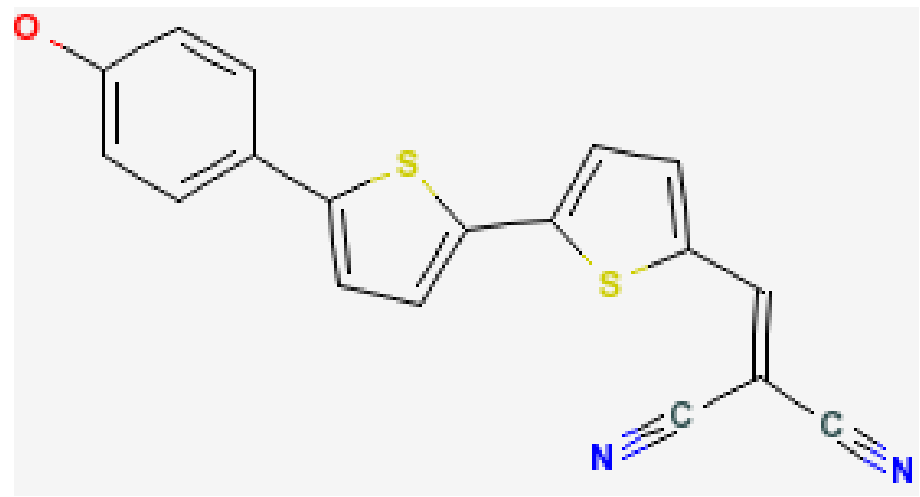


This molecule meets the above-mentioned requirements for a fluorescent molecular probe. Its specific structure and its rather low molecular weight (334 Da) make its rapid traverse through the BBB possible [26]. The structure of NIAD-4 core, somehow resembling that of Thioflavin $\mathrm{T}$ (see Figure 3), which is a well-known amyloid fibril detection agent, makes a highly specific binding with $\mathrm{A} \beta$ aggregates feasible.

Figure 3 - Thioflavin T

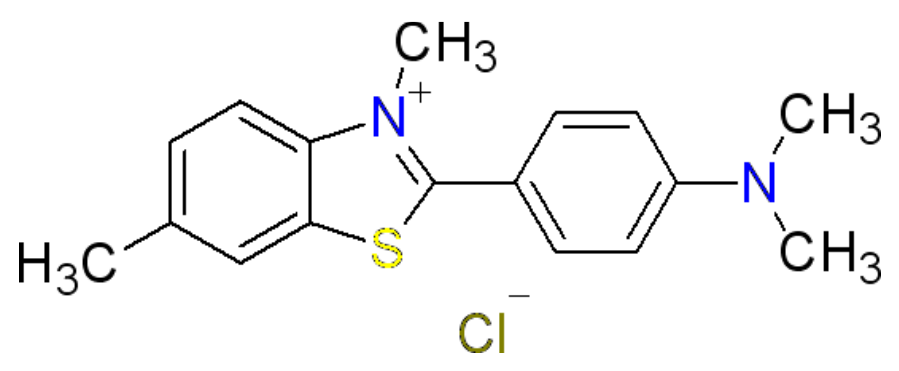

The NIAD-4 structural characteristics also make a quantum yield enhancement possible after binding. The in vivo tests of NIAD-4 in rat model of AD were promising. However, further work is needed to make this technique completely noninvasive by increasing the red shift and quantum yield [26].

Quantum dots are another group of nanotechnology-made fluorescent dyes [27-31]. These nanoscale semiconductor crystals have special fluorescent properties including minimal photo bleaching, optimal stability, high signal to noise ratio and broad absorption spectrum with very narrow but size-dependant tunable emission spectrum. These advantages over conventional fluorescent dyes [28] give QDs the potential for long-term tracking and simultaneous visualization of multiple physiological and pathological molecular events [29]. This simultaneous multiple labeling property is especially important for diagnosis of $\mathrm{AD}$, since there are several biomarkers in the AD pathology, and not only their existence but also their proportion to each other may be helpful for ruling out other differential diagnoses [1].

However, due to the toxicity of the semiconductor materials presently used in QDs, like cadmium selenide $(\mathrm{CdSe})$ and cadmium sulfate $(\mathrm{CdS})$, their in vivo applications are questionable. Of course, some investigators have reported reduction in the toxicity of QDs when encapsulated in polymers (like phospholipids) [30] or coated by polyethylin glycol (PEG) [31]. Tokurako et al. recently developed a nanoprobe for amyloid- $\beta$ aggregation and oligomerization using PEG coated QDs as $A \beta_{42}$ labels [32]. They examined the oligomerization behavior of $A \beta_{42}$ in solution and on intact cells and they compared the ingestion manner of microglia for $A \beta_{42}$ monomers and oligomers. However, in order to use this diagnostic technology to monitor $\mathrm{A} \beta_{42}$ biochemical behavior in vivo, in addition to $\mathrm{QD}$ safety considerations, special attention should be paid to successful traverse of this QD-A $\beta$ nanoprobes through the BBB. QDs conjugated with Transferrin were recently reported to be able to successfully transmigrate through an in vitro model of the BBB [33]. Further in vitro and in vivo research is required to evaluate similar approaches to transmigrate QD-based nanoprobes across the BBB [1].

In Table 1, we report all the available in vitro and in vivo $\mathrm{AD}$ diagnostic methods, in a comparative fashion based on the information available in the literature. Obviously, there is still a need for research to develop an affordable, ultra-sensitive and selective molecular AD detection method. 
Table 1. Suggested in vivo and in vitro nanotechnology methods for AD diagnosis

\begin{tabular}{|c|c|c|c|c|c|c|c|c|}
\hline \multirow[b]{2}{*}{$\stackrel{\vec{g}}{=}$} & \multirow[b]{2}{*}{ Technology } & \multirow[b]{2}{*}{ Biomarker } & \multirow[b]{2}{*}{ Signal Detection } & \multicolumn{2}{|c|}{ Signal transduction } & \multirow{2}{*}{$\begin{array}{c}\text { Signal } \\
\text { Documentation }\end{array}$} & \multirow[b]{2}{*}{ Sensitivity } & \multirow[b]{2}{*}{ 离 } \\
\hline & & & & $\begin{array}{c}\text { Signal } \\
\text { transform }\end{array}$ & $\begin{array}{c}\text { Signal } \\
\text { Amplification }\end{array}$ & & & \\
\hline \multirow{4}{*}{ 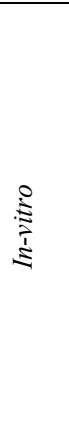 } & Bio-barcode assay & ADDL & $\begin{array}{c}\text { Sandwich assay } \\
\text { (Monoclonal Anti ADDL } \\
\text { Ab) }\end{array}$ & DNA barcode & $\begin{array}{c}\text { Functionalized } \\
\text { AuNP carrier } \\
\text { for numerous } \\
\text { DNA barcodes }\end{array}$ & $\begin{array}{l}\text { Scanometric } \\
\text { Recording }\end{array}$ & $\mathrm{aM}$ & (17) \\
\hline & $\begin{array}{l}\text { Localized surface } \\
\text { plasmon resonance }\end{array}$ & ADDL & $\begin{array}{c}\text { Sandwich assay } \\
\text { (Monoclonal \& Policlonal } \\
\text { Anti-ADDL Ab) }\end{array}$ & $\begin{array}{l}\text { Wavelength } \\
\text { shift }\end{array}$ & $\begin{array}{l}\text { Secondary Ab } \\
\text { of Sandwich } \\
\text { assay }\end{array}$ & Spectroscopy & N/A & (18) \\
\hline & $\begin{array}{l}\text { Scanning Tunneling } \\
\text { Microscopy }\end{array}$ & $\mathrm{A} \beta_{(1-42)}$ & $\begin{array}{c}\text { Sandwich assay } \\
\text { (Monoclonal Anti } \mathrm{A} \beta \mathrm{Ab} \text { ) }\end{array}$ & $\begin{array}{c}\text { Tunneling } \\
\text { Current Change }\end{array}$ & $\begin{array}{l}\text { Silver Staining } \\
\text { of AuNPs }\end{array}$ & $\begin{array}{c}\text { Frequency of } \\
\text { pulse-like peaks }\end{array}$ & $10 \mathrm{fg} / \mathrm{ml}$ & (25) \\
\hline & $\begin{array}{l}\text { Two Photon Rayleigh } \\
\text { Scattering Assay }\end{array}$ & Tau protein & Monoclonal Anti-Tau Ab & $\begin{array}{l}\text { TPRS intensity } \\
\text { change }\end{array}$ & TPRS & $\begin{array}{c}\text { TPRS } \\
\text { Spectroscopy }\end{array}$ & $1 \mathrm{pg} / \mathrm{ml}$ & (20) \\
\hline \multirow{2}{*}{$\begin{array}{l}0 \\
: \\
1 \\
\Sigma \\
\Sigma\end{array}$} & $\mu \mathrm{MRI}$ & $\mathrm{A} \beta$ plaques & $\mathrm{A} \beta$ peptide & $\begin{array}{c}\text { Magnetic } \\
\text { heterogeneity }\end{array}$ & N/A & MRI scanner & N/A & $\begin{array}{l}(23, \\
24)\end{array}$ \\
\hline & $\begin{array}{l}\text { Optical (Fluorescent) } \\
\text { Imaging }\end{array}$ & $\mathrm{A} \beta$ plaques & NIAD-4 & $\begin{array}{l}\text { Fluorescent } \\
\text { excitation }\end{array}$ & $\begin{array}{l}\text { Upon Binding } \\
\text { Molecular } \\
\text { Rigidification }\end{array}$ & $\begin{array}{l}\text { multiphoton } \\
\text { microscopy }\end{array}$ & N/A & (26) \\
\hline
\end{tabular}

\section{Nanotechnology-based Treatments for Alzheimer's Disease}

As we discussed before, the currently available therapeutics for $\mathrm{AD}$, only act to lower its symptoms $[1,8]$. In recent years, however, significant amount of research have been focused on finding the socalled "neuroprotective agents", therapeutics that could stop the disease progress by targeting special molecular mechanisms in the AD pathology process [1,34]. However, more futuristic are approaches that could rebuild the damaged tissue, called as "regenerative agents". These two (neuroprotective and neuroregenerative) approaches together are known as "disease-modifying approaches". They are distinguished from symptomatic approaches by the fact that in addition to ameliorating the symptoms they are aimed to stop the disease progress and restore the dysfunctional or dead tissue [34].

The therapeutic potential of nanotechnology for AD includes both neuroprotective and neuroregenerative approaches [1]. In addition, nanotechnology has shown promising applications in targeted drug delivery for $\mathrm{AD}$, and several nanocarrier systems have been studied in recent years to increase the bioavailability and efficacy of different AD therapeutic agents [1]. 
Figure 4 - In this figure the interaction of $\mathrm{Fe}^{3+}$ and $\mathrm{Cu}^{2+}$ with $\mathrm{A} \beta$ leading to the production of oxidative stress is shown. $A \beta$ can also oligomerize in the lipid bilayer of cell plasma membrane, leading to formation of membrane calcium channels [35]. These calcium channels cause an imbalance in calcium homeostasis [36], that ends in oxidative stress. In addition, the membrane integrated $A \beta$ can chemically interact through (amino acid) Methionine 35 (not shown) with the membrane lipid molecules and the resultant lipid peroxidation produces 4-hydroxy-2-nonenal (4HNE) [37]. Such an interaction leads to membrane disruption and production of reactive oxygen species and finally oxidative stress in the involved brain tissue. The $4 \mathrm{HNE}$ and other reactive oxygen species (ROS) also lead to tau phosphorylation and aggregation. Moreover, intracellular aggregates of $A \beta$ cause mitochondrial oxidative stress, and further imbalance in $\mathrm{Ca}^{2+}$ hemostasis. The resultant impairment of electron transfer chain leads to overproduction of superoxide anion, which is converted either to $\mathrm{H}_{2} \mathrm{O}_{2}$ or to peroxynitrite $\mathrm{ONOO}$ (following interaction with nitric oxide (NO)). The interaction of $\mathrm{H}_{2} \mathrm{O}_{2}$ with $\mathrm{Fe}^{2+}$ or $\mathrm{Cu}^{2+}$ produces the hydroxyl radical $\left(\mathrm{OH}^{*}\right)$, a strong ROS that induces membrane-associated oxidative stress [38]

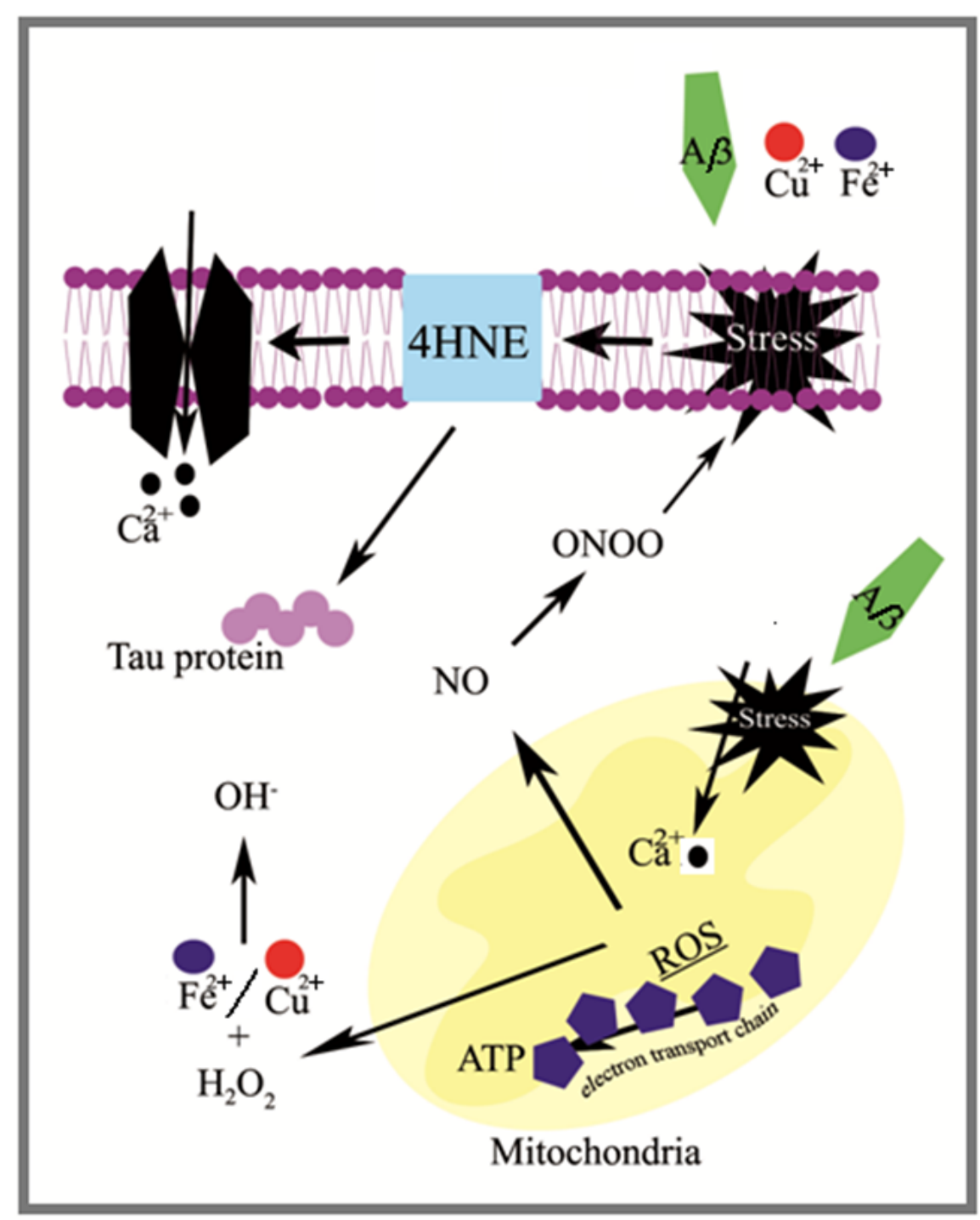




\subsection{Nanotechnology Neuroprotective Potentials}

The main two sources of neurotoxicity in $\mathrm{AD}$ pathogenesis are $\mathrm{A} \beta$ oligomers and free radicals (see Figure 4). Some of the nanotechnology-based approaches are capable of protecting neurons from $A \beta$ toxicity by preventing from amyloid oligomerization (anti-assembly strategy) and/or accumulation of $\mathrm{A} \beta$ oligomeric species [1]. The other nanotechnology neuroprotective approaches include those that protect neurons from oxidative stress of free radicals [1].

\subsubsection{Nanogels}

The work of Ikeda et al. is an example for the A $\beta$ anti-assembly strategy [39]. They designed an amphipathic nanogel that incorporates proteins and controls their folding and aggregation, similar to natural chaperones (proteins assisting the non-covalent folding and/or unfolding). In the case of $A \beta$, these nanogels would inhibit the amyloidogenesis process effectively through this mechanism (see Figure 5).

Figure 5 - (a). Schematic representation of the interactions between artificial nanoscale chaperone system and misfolded $A \beta$. (b). Refolded $A \beta$ monomers are released after addition of cyclodextrin.

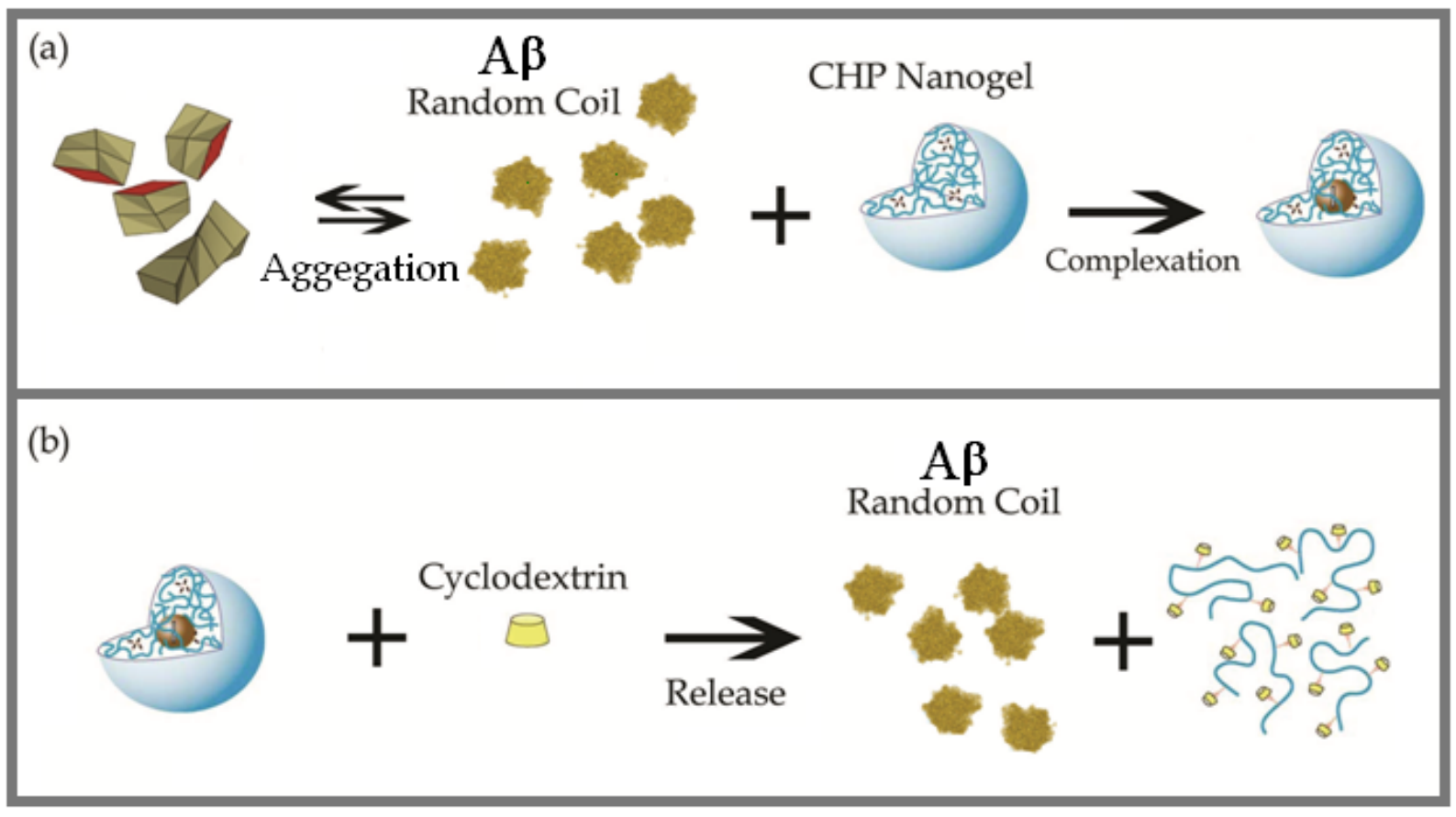

The nanogel (hydrogel nanoparticles) designed in this study was composed of cholesterol bearing pullulan (CHP). Pullulan is a natural water-soluble polysaccharide polymer consisting of maltotriose (a trisaccharide consisting of three glucose molecules linked with 1,4 glycosidic bonds) units. Inhibiting assembly at the monomer level, this technique prevents $A \beta$ oligomerization and therefore reduces the concentration of toxic $A \beta$ oligomeric species [1]. Recently, Boridy et al. demonstrated a significant reduction in $A \beta_{42}$ toxicity in the primary cortical cell culture and microglial cell culture after using CHP nanogels [40]. 


\subsubsection{Fullerene}

Fullerene $\left(\mathrm{C}_{60}\right)$ and its derivatives could be the base of neuroprotective compounds [41]. The biological applications of fullerene, including its anti-oxidant and free radical scavenger potentials, are due to its kind of chemical structure that allows it to be linked (and to be functionalized) by several active chemical groups in a 3-dimensional orientation $[12,14]$. Dugan et al. demonstrated the effects of carboxyfullerenes (malonic acid derivative of $\mathrm{C}_{60},\left\{\mathrm{C}_{63}\left[(\mathrm{COOH})_{2}\right]_{3}\right\}$ ) on $\mathrm{A} \beta_{42}$ induced oxidative stress and neurotoxicity in cultured cortical neurons [41, 42]. Interestingly, the application of carboxyfullerenes blocked the $A \beta_{42}$ induced neuronal apoptotic death [42].

Podolski et. al. demonstrated anti-assembly effect of $\mathrm{C}_{60}$ hydrated fullerene $\left(\mathrm{C}_{60} \mathrm{HyFn}\right)$ on the fibrillization of $A \beta_{25-35}$ fragment. It was demonstrated that injection of $3.6 \mathrm{nMol}$ of $\mathrm{C}_{60} \mathrm{HyFn}$ to each of the brain ventricles could prevent the cognitive impairment in rats previously injected with $A \beta_{25-35}$ fragment [43].

Fullerene has also complete neuroprotective properties against NMDA receptor mediated neurotoxicity according to the studies of Dugan et al. [44]. NMDA receptor function is important to neuronal mechanisms of learning and memory.

Fullerenols, which are water-soluble hydroxyl functionalized derivatives of fullerene, have shown neuroprotective properties against $A \beta_{42}$. Presumably, the neuroprotective effect of fullerenols is due to, both, anti-oxidant reactions and inhibition of $\mathrm{A} \beta_{42}$-induced $\mathrm{Ca}^{2+}$ neurotoxicity. Huang et al. validated the latter finding in their investigation into the effect of fullerenol-1 upon $A \beta$-induced $\mathrm{Ca}^{++}$influx in the cultured neurons [45].

Altogether, promising applications of functionalized fullerene derivatives including carboxyfullerene, hydroxyfullerene (fullerenols) and $\mathrm{C}_{60} \mathrm{HyFn}$ are in discovery of new drugs for $\mathrm{AD}$. However further research on their pharmacodynamic and pharmacokinetic properties is necessary [1].

\subsubsection{Nano-Ceria}

Cerium oxide $\left(\mathrm{CeO}_{2}\right)$ nanoparticle (nano-ceria) is reported to have neuroprotective effects on $\mathrm{AD}$ in vitro models [46]. This is mainly due to the anti-oxidant properties of nano-ceria, originating in the two oxidation-reduction (redox) states of cerium: $\mathrm{Ce}^{2+}$ and $\mathrm{Ce}^{4+}$ and the resultant oxygen vacancies $[36,47]$. D'Angelo et al. showed that in addition to the mentioned anti-oxidant properties, nano-ceria protects neurons from cytotoxic effects of $A \beta$ via modulating the intracellular signaling pathways involved in cellular death and neuroprotection [46].

\subsubsection{Dendrimers}

Dendrimers, one of the polymeric nanotechnology building blocks [48, 49], are macromolecular structures with globular shape and a densely packed surface [50]. Their structure has offered them a number of biomedical potentials [48, 49]. Recently, a multipurpose anti-amyloid strategy was suggested for dendrimers [50]. A $\beta$ anti-assembly strategy of dendrimers could be performed either via their binding with peptide monomers or through blocking the end of protofibrils and fibrils. Prevention from cytotoxic effects of $\mathrm{A} \beta$ is another prospect of nanotechnology and application of modified dendrimers is a recent suggestion for this approach. Patel et al. demonstrated that dendrimers (both conjugated and unconjugated) could shield the cell membrane from A $\beta$ membrane mediated 
neurotoxicity, which is due to $A \beta$ electrostatic interaction with the cell membrane [51]. In addition, dendrimers could sequester the $A \beta$ toxic species and therefore block their pathological effects on the cell membrane. However, because of the probable toxic effect of dendrimers on cells, this method needs further investigation for in vivo application.

\subsubsection{Gold Nanoparticles}

Resolubilization of fibrillar amyloid species is another nanotechnology suggested anti-amyloid approach. Kogan et al. utilized gold nanoparticles (AuNPs) in weak microwave fields in order to dissolve amyloid aggregates [52]. Their design was based on dissolving $A \beta$ aggregates and prevention from further $A \beta$ aggregations by providing local thermal energy at a molecular level. The AuNPs, already attached to the specific target (i.e. A $\beta$ ), produce the thermal energy when a weak microwave field is surrounding. The nanometric size, high surface-to-volume ratio, biocompatibility and mobility of AuNPs make them suitable for providing a specific bond target with a selective supply of energy in a remotely controlled manner, and without any adverse effects on the proximity molecules. Each AuNP provided a dissipating thermal energy of $10^{-14} \mathrm{~J} / \mathrm{s}$, capable of breaking a fibril (non-covalent) bond $\left(10^{-20} \mathrm{~J}\right.$ binding energy per bond) per microsecond without breaking the covalent bonds, which are two orders of magnitude stronger [52]. However, according to the cytotoxic effects of $A \beta$ oligomeric species, the targeting must be arranged exclusively for these species. Otherwise, if the fibrillar species are targeted conversely, the toxic effects will increase due to an accumulation of $A \beta$ oligomeric species, following the breakdown of the fibrillar species [1]. Therefore, the method of Kogan et al. seems to be advantageous for noninvasive investigation and manipulation of $\mathrm{A} \beta$ aggregates in $\mathrm{AD}$, provided the appropriate amyloid species is targeted.

\subsubsection{Diamondoid Derivatives}

Diamondoids are in the category of most promising molecular building blocks in nanotechnology and specially nanomedicine [53]. Diamondoids and their derivatives are the basis of many varieties of anti-viral and anti-bacterial drugs, already in the market or in various developmental stages. A diamondoid-based drug (memantine), which is already in commercial use, slows down the progression of the Alzheimer's disease [54]. Memantine [1-amino-3, 5-dimethyladamantane] with Namenda as its commercial name (Figure 6) is an FDA-approved drug for treatment of moderate to severe Alzheimer's disease. Memantine acts as a neuroprotective agent against excitotoxicity, an excessive exposure to the excitatory neurotransmitter, glutamate, or overstimulation of its membrane receptors, leading to neuronal injury or death. Excitotoxic neuronal cell death is mediated, in part, by overactivation of Nmethyl-d-aspartate (NMDA)-type glutamate receptors. Nevertheless, NMDA receptor activity is also essential for normal neuronal function. This means that potential neuroprotective agents that block virtually all NMDA receptor activity will very likely have unacceptable clinical side effects. Memantine preferentially blocks excessive NMDA receptor activity without disrupting normal activity [55]. 
Figure 6 - Memantine (1-amino-3, 5- dimethyladamantane), commercially known as Namenda, a synthetic adamantane derivative with biological activity on the central nervous system.

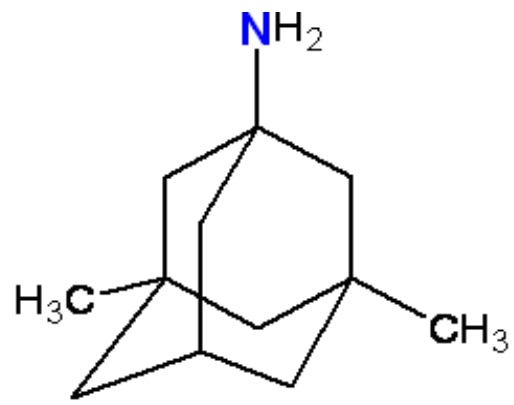

Although memantine is already approved by FDA for Alzheimer's disease treatment, studies are underway for other diamondoid derivatives which could have stronger neuroprotective and possibly regenerative capability as well as their application for the treatment of diseases related to glutamatergic dysfunction.

In Table 2, we report a comparison of the above discussed six nanotechnology neuroprotective agents for treatment of $\mathrm{AD}$, which include their neuroprotective functions, the mechanisms of their targeted AD pathology and their stage of study modes.

Table 2- Nanotechnology neuroprotective agents for treatment of AD

\begin{tabular}{|c|c|c|c|c|}
\hline Nanosystem & $\begin{array}{c}\text { Neuroprotective } \\
\text { Function }\end{array}$ & $\begin{array}{c}\text { Targeted AD pathology } \\
\text { mechanism }\end{array}$ & Study Mode & Ref.s \\
\hline $\begin{array}{l}\text { Nanogels (Cholesterol bearing } \\
\text { pullulan) }\end{array}$ & $\begin{array}{c}\mathrm{A} \beta \text { Anti-assembly } \\
\text { (Incorporate } \mathrm{A} \beta \\
\text { monomers) }\end{array}$ & Oligomerization of $A \beta$ & $\begin{array}{c}\text { In vitro } \\
\text { (Solution and } \\
\text { Cell Culture) }\end{array}$ & (39) \\
\hline $\begin{array}{l}\text { Fullerene }\left(\mathrm{C}_{60}\right): \\
\text { Carboxyfullerene, } \\
\mathrm{C}_{60} \mathrm{HyFn}, \\
\text { Fullerenol }\end{array}$ & $\begin{array}{c}\text { Anti-oxidant } \\
\text { A } \beta \text { Anti-Assembly } \\
\text { Anti-oxidant / } \\
\text { Maintenance of } \mathrm{Ca}^{2+} \\
\text { homeostasis }\end{array}$ & $\begin{array}{c}\text { Oxidative stress } \\
\text { Oligomerization of } \mathrm{A} \beta \\
\mathrm{Ca}^{++} \text {influx }\end{array}$ & $\begin{array}{l}\text { In vitro (cell } \\
\quad \text { culture) } \\
\text { In vivo (Rats) }\end{array}$ & $(41-45)$ \\
\hline $\begin{array}{l}\text { Dendrimers: } \\
\text { Polyamidoamine (PAMAM)) }\end{array}$ & A $\beta$ Anti-Assembly & $\begin{array}{c}\text { Oligomerization of } A \beta \\
A \beta \text { cell memberane toxicity }\end{array}$ & In vitro & $(48,49)$ \\
\hline Nanoceria $\left(\mathrm{CeO}_{2}\right)$ & Anti-oxidant & Oxidative Stress & In vitro & $(46,47)$ \\
\hline Gold Nanoparticles (AuNP) & A $\beta$ Anti-Assembly & Oligomerization of $\mathrm{A} \beta$ & In vitro & (52) \\
\hline $\begin{array}{l}\text { Diamondoid Derivatives } \\
\text { (Memantine) (1-amino-3, 5- } \\
\text { dimethyladamantane) }\end{array}$ & $\begin{array}{l}\text { NMDA receptor } \\
\text { antagonism }\end{array}$ & Glutamate excitetoxicity & $\begin{array}{l}\text { In vivo (FDA } \\
\text { approved) }\end{array}$ & (54) \\
\hline
\end{tabular}

\subsection{Nanocarriers}

Targeted drug delivery is an important application of nanomedicine [56]. With regard to diseases of central nervous system (CNS) it is appreciably complicated due to the additional obstacle of the blood brain barrier (BBB) against the entry of a variety of molecules into the CNS tissue [57]. The use of biocompatible nanoparticles to facilitate the traverse of therapeutic agents across BBB has been extensively researched in the past decade [58]. In what follows, we discuss nanocarrier systems suggested for delivery of therapeutic agents for AD into the brain. 


\subsubsection{Curcuminoids Nanocarrier}

Curcumin, with the chemical formula reported in Figure 7, is the active ingredient of turmeric, the yellow spice which has been recently discovered as a potential treatment for AD [59].

Figure 7 - Curcumin<smiles>COc1cc(/C=C/C(=O)CC(=O)/C=C/c2ccc(O)c(OC)c2)ccc1O</smiles>

This agent acts through several mechanisms including anti-amyloid assembly, anti-oxidant and antiinflammatory [59]. However, this agent is unstable due to rapid hydrolyzation or oxidization. Therefore, Poly n-butylcyanoacrylate (PnBCA) (Figure 8) nanocapsules have been used to carry these therapeutic agents through the $\mathrm{BBB}$. These nanocapsules were coated by the protein ligand named apolipoprotein E3 (APoE-3), in order to use LDL receptors for the BBB crossover [60].

Figure 8 - Poly n-butylcyanoacrylate (PnBCA)

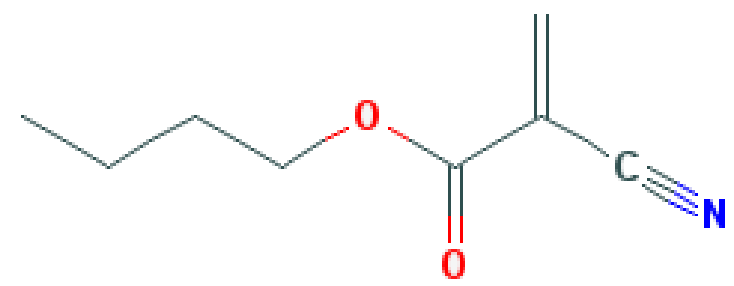

\subsubsection{Cholinesterase Inhibitors Nanocarriers}

Deficiency in the cholinergic neurotransmission is the principal neurochemical feature of $\mathrm{AD}$, and the current main therapeutic agents against $\mathrm{AD}$ are targeting this deficiency. These drugs, known as acetylcholinesterase inhibitors (AChEIs), inhibit the enzyme that degrades the acetylcholine neurotransmitter (i.e. acetylcholinesterase). However, the efficacy of these drugs is significantly compromised by BBB, impeding their entrance into the brain. Therefore, higher doses, at which peripheral side effects occur, are needed. Recently some nanocarrier systems were suggested to transport these therapeutic agents beyond BBB [61]. Wilson et al. demonstrated 3.8 and 4 fold increase in the brain delivery of two of these AChEIs (Rivastigmine and Tacrine, respectively), by exploiting polysorbated 80-coated polymeric Poly n-butylcyanoacrylate (PnBCA) nanocapsules [62]. These PnBCA nanocarriers use the LDL receptors to transport through BBB. 


\subsubsection{Acetylcholine Nanocarrier}

Yang et al. have recently introduced a nanocarrier system for delivery of acetylcholine to lysosomes in brain of mice model of AD through low doses of single-wall carbon nanotubes (SWCN) [63]. The advantage of SWCN is the possibility of their oral administration owing to their sufficient gastrointestinal absorption. Although no significant SWCN induced toxicity is reported at their low doses, considering their biologically non-degradable nature, further research on their safety is in demand [61].

\subsubsection{Hormone Nanocarriers}

Recent investigations have revealed that sex steroid hormones, especially estrogen and andorgens could have neuroprotective effects against several $\mathrm{AD}$ pathogenic mechanisms, including $\mathrm{A} \beta$ accumulation, cytotoxicity and neurotoxicity [64]. However, there are serious concerns about their side effects due to their uptake by other tissues. Targeted delivery of these potential drugs is what nanotechnology provides to minimize their complications. Chitosan and poly(lactide-co-glycolide acid) (PLGA) nanoparticles are two nanocarriers recently suggested and examined for delivery of sex steroid hormones (e.g. Estradiol) to the brain [65]. In the study of Wang et al. it was shown that intranasal administration of Estradiol loaded Chitosan nanoparticles could significantly increase the CSF concentration of the drug, with minimal increase in plasma concentrations, and therefore minimizing its peripheral side effects [66]. Two other studies have demonstrated a considerable increase in bioavailability of estradiol and mifepristone, after oral administration, when encapsulated

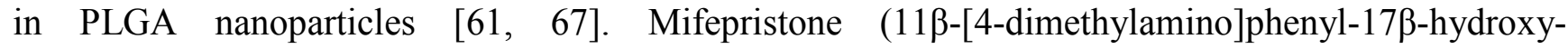
17[propynyl] estra-4,9-dien-3-one) is an anti-progestrone compound which is reported to slow the cognitive impairment progress in $\mathrm{AD}$ patients [68].

\subsubsection{Green Tea Polyphenol Nanocarrier}

Recently, the green tea polyphenol, epigallocatechin-3-gallate (EGCG), was discovered to have therapeutic effects for $\mathrm{AD}$ [69]. In addition to anti-oxidant effects, EGCG is capable of reducing $\mathrm{A} \beta$ production. $A \beta$ is known to originate from sequential cleavage of A $\beta$ precursor protein (APP) by $\beta$ secretase and then $\gamma$-secretase [70]. APP could also be cleaved, instead of $\beta$-secretase, by another proteolytic enzyme termed as $\alpha$-secretase. In this case, further cleavage of the remnant by $\gamma$ - secretase results in a protein called P3 and not A $\beta$. It is reported that EGCG could promote $\alpha$-secretase and thus deviate the APP cleavage process from production of $A \beta[69]$. However, due to its low bioavailability, EGCG alone could not be of therapeutic value if taken orally. In order to solve this problem, recently, Smith et al. co-solubilized EGCG with lipid nanocarrier and made EGCG:lipid complexes (nanolipidic particle) with a diameter of 30-80 $\mathrm{nm}$ [71]. With this new formulation, they showed an increase in bioavailability of EGCG and suggested a probable increase in EGCG brain uptake due to its very small size. 


\subsubsection{Chelator Nanocarriers}

Brain normally contains a certain trace concentration of metal ions like $\mathrm{Zn}^{++}, \mathrm{Cu}^{++}$and $\mathrm{Fe}^{++}$, which possess different physiological roles [72]. Of course, these trace metal ions are kept under strict homeostatic regulations and compartmentalization. Any disruption in the homeostasis of these trace elements leading to higher concentrations of these ions, may impose several proteins and membrane lipids to toxic effects of these trace elements and finally end in production of ROS [72-75] (see Figure 4).

Amyloid- $\beta$ peptide $(A \beta)$ has some selective metal binding sites, and it is actually a metalloprotein from this point of view. It is known that even trace amounts of $\mathrm{Zn}^{++}$and $\mathrm{Cu}^{++}$that may be released from synaptic terminals of brain cortical neurons could induce $A \beta$ aggregation (and then precipitation) via interactions with $A \beta$ histidine amino acid [72]. This precipitation is reversible by metal chelation before fibrillization happens. In addition, the interaction of $\mathrm{Fe}^{+++}$and $\mathrm{Cu}^{++}$with $\mathrm{A} \beta$ may lead to production of $\mathrm{H}_{2} \mathrm{O}_{2}$ due to double electron transfer to $\mathrm{O}_{2}$ [72] (see Figure 4). The production of $\mathrm{H}_{2} \mathrm{O}_{2}$ is partly responsible for oxidative injury seen in $\mathrm{AD}$. Furthermore, the interaction of $\mathrm{A} \beta$ with cell membrane is enhanced by $\mathrm{Zn}^{++}$and $\mathrm{Cu}^{++}$[82], and $\mathrm{Cu}^{++}$could play an important role in the neurotoxicity of $A \beta[77]$.

Metal chelation, which stands for the clearance of body tissues from excessive metal ions, could therefore be considered as one of the disease modifying agents for AD [72]. An efficient metal chelation strategy for $\mathrm{AD}$ may substantially decrease both the extracellular oxidative stress and $\mathrm{A} \beta$ aggregation, and therefore slow down the AD progress. For most current metal chelators, however, this is not the case, and there are some obstacles to an efficient therapeutic response. These obstacles include risk of non-specific metal chelation from other tissues, difficulty in passing through the BBB, and pooling of metal ions into amyloid plaques [72]. Nanotechnology approaches are recently used in some studies to engineer chelator therapeutic systems that overcome these obstacles [76]. Below we report the role of iron and copper chelators in $\mathrm{AD}$ modification.

\subsubsection{Iron Chelators:}

Liu et al. conjugated Desferrioxamine (also named as DFO-B, DFB, desferal, desferrioxamine B, or desferoxamine B), an FDA approved metal chelator, with nanoparticles (through an amido bond between a primary amino group in the chelator and a carboxyl group on the nanoparticle surface) to produce an efficient chelator nanoparticle system (CNPS) [79]. They reported that the chelation effect of metal chelator was retained after formation of CNPS. In addition to feasibility of carrying iron chelators across BBB, their work showed other advantages of nanoparticle technology. For instance, it was shown that the iron chelating CNPS was able to traverse the BBB in the reverse direction by preferential adsorption of Apo A-I and thereby removal through LDL transport system. Moreover, it was suggested that the inherent toxicity of the chelators are obviously decreased after conjugation with nanoparticles [80].

Later, Liu et al. suggested another synthesized nanoparticle-chelator conjugate (named Nano$\mathrm{N} 2 \mathrm{PY}$ ), and demonstrated its in vitro ability to inhibit the cytotoxic effects of $A \beta$ on human cortical neurons [81]. The nanoparticles used in this study were made of carboxyl functionalized polystyrene. The mechanism of such anti-cytotoxic effect of the Nano-N2PY was probably related to its preventive 
effect on the $A \beta$ aggregation. In addition, such a nanoparticle conjugate is capable of transporting metal chelators across the BBB, without disrupting the metal binding feature of the chelator. In addition to increasing the efficacy of metal chelating strategy, these nanoparticle conjugates were shown to reduce the toxicity of chelation strategy, by decreasing the lipophilicity of the chelators [81].

\subsubsection{Copper Chelators:}

In the study of Cui et al. [82] d-penicillamine (which is a degradation product of penicillin), an FDA approved drug for chelation of copper in Wilson's disease (an inherited disorder in which there is too much copper in the body's tissues), was examined as a metal chelator in AD. The conjugation of d-penicillamine with the nanoparticles containing, 1,2-Dioleoyl-snglycero-3-phosphoethanolamine-N-[4-(p-maleimidophenyl)butyramide], known as MPB-PE and pyridyldithio-propionylhosphoethanolamine known as PDP-PE enabled the traverse of d-penicillamine through the BBB in spite of its highly hydrophilic properties. This study showed the ability of d-penicillamine for chelating copper and desolubilizing $A \beta_{42}$. Cui et al. demonstrated in this study that, interestingly, the BBB integrity and permeability remained unchanged and no changes in the cerebral perfusion flow were evident. Therefore, it is suggested that the transport mechanism for this nanoparticle formulated carrier system is endocytosis, transcytosis or passive diffusion in the absence of barrier opening [82].

\subsubsection{Anti-Oxidant Nanocarrier Agents}

In addition to the above mentioned anti-oxidant nanotechnology building blocks, solid lipid nanoparticles (SLN) have been recently employed to improve the delivery of anti-oxidant agents [83, 84]. SLN is considered one of the safe nanoparticles suggested for drug delivery to the brain [58]. In the study of Bondi et al, SLN played the role of a nanocarrier for ferulic acid [3-(4-hydroxy-3methoxyphenyl)-2-propenoic acid], a phenolic compound with a strong anti-oxidant activity [84]. The resultant nano-complex possesses a small colloidal surface with a highly negative surface charge when dispersed in water [83]. The effects of ferulic acid (FA), including reduced ROS production, normalized mitochondrial membrane potential and decreased cytochrom $\mathrm{C}$ release, all caused an increased cell viability in the experiment of exposure of neuroblastoma cells to $A \beta_{42}$ oligomers [83]. Enhancing the drug stability within biological fluids and making intracellular targeting feasible, the SLN nanocarrier improved the anti-oxidant effects of FA [83, 84].

\subsubsection{Gene Nanocarriers}

The main part of gene therapy is gene delivery, through which the genetic material will be presented inside a cell [85]. In order to protect the genetic material from biological obstacles, like cell membrane charge and enzymatic degradation, a carrier should accompany the genetic material. So far, most of the gene therapy studies for AD have employed viral vectors. However, due to the health risks associated with viral vectors, and also the limitations in size and number of genetic inserts through viral vectors, using alternative non-viral vectors have become the focus of attention in recent years [85]. On the other hand, usage of nanoparticles as nonviral gene carriers has significantly improved the efficacy of this method by minimizing the enzymatic degradation of genetic materials [85-87] In particular, 
polymeric, ceramic and amino-terminated organically modified silica (ORMOSIL) nanoparticles have recently shown some promise in gene transfer to the CNS [85]. For example, polyethyleneimine is a polymeric nanoparticle, capable of forming stable complexes with nucleic acid and easily releasing from endosomes, both due to its protonable amino nitrogen atoms that make this cationic nanoparticle a "proton sponge" at any $\mathrm{pH}$ [88]. Boussif et al. reported the successful gene transfection to neurons and also a high efficiency of in vivo gene transfection through polyethyleneimine vector [88]. The more promising of all, ORMOSIL nanoparticles, was first examined for in vivo gene delivery to CNS by Bharali et al. [89]. In this study the ORMOSIL nanoparticles were functionalized with amino groups for DNA binding. Their experiment indicated that these nontoxic nanoparticles were appropriate gene vectors not only for in vivo brain therapy but also for therapeutic regulation of neural stem cells.

In Table 3, we compare the above discussed nanocarrier systems suggested for delivery of therapeutic agents for $\mathrm{AD}$ into the brain.

Table 3 - Summary of Applicable Nanocarrier Systems in AD Treatment

\begin{tabular}{|c|c|c|c|c|c|c|}
\hline Nanocarrier & Structure & Size $[\mathrm{nm}]$ & $\begin{array}{l}\text { BBB transport } \\
\text { mechanism }\end{array}$ & $\begin{array}{l}\text { Loaded } \\
\text { Drug(s) }\end{array}$ & $\begin{array}{c}\text { Therapeutic } \\
\text { Effect/Category }\end{array}$ & Ref. \\
\hline \multirow{2}{*}{$\begin{array}{c}\text { PnBCA } \\
\text { nanocapsule }\end{array}$} & \multirow{2}{*}{$\begin{array}{l}\text { Polysorbated } 80 \text {-coated } \\
\text { polymeric Poly n- } \\
\text { butylcyanoacrylate }\end{array}$} & $40.5 \pm 0.6 .9$ & \multirow{2}{*}{ LDL transport system } & $\begin{array}{l}\text { Rivastigmine } \\
\text { Tacrine }\end{array}$ & $\begin{array}{l}\text { Acetylcholinesterase } \\
\text { inhibitors }\end{array}$ & $(61,62)$ \\
\hline & & $\begin{array}{c}178 \pm 0.59 \\
\text { to } \\
197 \pm 2.3 \\
\end{array}$ & & Curcumin & $\begin{array}{l}\text { Anti-amyloid assembly, } \\
\text { Anti-oxidant and anti- } \\
\text { inflammatory }\end{array}$ & $(60)$ \\
\hline SWCN & Single-wall carbon nanotubes & $\begin{array}{l}0.8-1.2 \\
\text { diameter } \\
\text { and } \\
\text { several } \\
\text { microns } \\
\text { length } \\
\end{array}$ & $\begin{array}{l}\text { Entering brain through } \\
\text { nerve axons } \\
\text { (cytoplasmic } \\
\text { translocation) }\end{array}$ & acetylcholine & Neurotransmitter & (63) \\
\hline Chitosan & $\begin{array}{l}\text { linear polysaccharide formed } \\
\text { of randomly distributed } \beta-(1- \\
\text { 4)-linked D-glucosamine and } \\
\text { N-acetyl-D-glucosamine }\end{array}$ & $\begin{array}{c}\text { About } \\
200 \text { to } 500\end{array}$ & Unknown & Estradiol & $\begin{array}{l}\text { Neuroprotection against } \\
\mathrm{A} \beta\end{array}$ & $(66)$ \\
\hline PLGA & poly(lactide-co-glycolide acid) & $126.0 \pm 2.6$ & Unknown & $\begin{array}{l}\text { Mifepristone } \\
\text { Estradiol }\end{array}$ & $\begin{array}{c}\text { Slowing the cognitive } \\
\text { impairment progress in } \\
\text { AD }\end{array}$ & $(61,67)$ \\
\hline $\begin{array}{c}\text { Nanolipidic } \\
\text { particle }\end{array}$ & Lipid co-solubilized with drug & $30-80$ & Unknown & $\begin{array}{l}\text { Polyphenol } \\
\text { (EGCG) }\end{array}$ & reducing $A \beta$ production & (71) \\
\hline Nano-N2PY & $\begin{array}{c}\text { Carboxylic functionalized } \\
\text { polystyrene nanoparticles } \\
\text { Activated by N-cyclohexyl- } \\
\mathrm{N} \\
-(2- \\
\text { morpholinoethyl)carbodiimide } \\
\text { methyl-ptoluensulfonate } \\
\text { (CMC) }\end{array}$ & $\sim 240$ & Unknown & $\begin{array}{c}\text { 2-methyl-N- } \\
(2 \\
\text {-aminoethyl)-3- } \\
\text { hydroxyl-4- } \\
\text { pyridinone } \\
\text { (MAEHP) }\end{array}$ & Iron chelator & $(81)$ \\
\hline $\begin{array}{l}\text { MPB-PE/ } \\
\text { PDP-PE }\end{array}$ & $\begin{array}{l}\text { 1,2-Dioleoyl-snglycero-3- } \\
\text { phosphoethanolamine-N-[4- } \\
\text { (p- } \\
\text { maleimidophenyl)butyramide] } \\
\text { / pyridyldithio-propionyl- } \\
\text { phosphoethanolamine }\end{array}$ & $\begin{array}{c}103 \pm 33 \text { to } \\
117 \pm 44\end{array}$ & $\begin{array}{l}\text { Endocytosis, } \\
\text { transcytosis or passive } \\
\text { diffusion }\end{array}$ & d-penicillamine & $\begin{array}{l}\text { Chelating copper and } \\
\text { desolubilizing } A \beta_{42}\end{array}$ & $(82)$ \\
\hline $\begin{array}{c}\text { Solid lipid } \\
\text { nanoparticle } \\
(\mathrm{SLN}) \\
\end{array}$ & $\begin{array}{c}\text { Solid hydrophobic core having } \\
\text { a monolayer } \\
\text { of phospholipid coating. }\end{array}$ & $94-140$ & $\begin{array}{c}\text { Endocytosis, } \\
\text { transcytosis or passive } \\
\text { diffusion } \\
\end{array}$ & Ferulic acid & Anti-oxidant & $(83,84)$ \\
\hline ORMOSIL & $\begin{array}{l}\text { Ceramic and amino-terminated } \\
\text { organically modified silica }\end{array}$ & $\sim 30$ & N/A & DNA & Gene therapy & $(89)$ \\
\hline
\end{tabular}




\section{Conclusions}

Early diagnosis of $\mathrm{AD}$ would be a cost effective approach in order to prevent its irreversible and uncontrollable consequences. Early diagnosis need to be performed before the underlying pathology has become severe enough to present itself clinically. Several molecular biomarkers are recognized to be associated with the pathology of AD. However, the currently available laboratory methods are not sensitive enough for such an early diagnosis. Nanotechnology offers a number of highly sensitive molecular detection tools that may make this goal achievable. These nanodiagnostic tools utilize different nanoparticles/nanostructures, and are based on different physicochemical interactions that may be utilized either in vitro or in vivo.

Alzheimer's disease seems to be a multi-factorial disease with several pathogenetic mechanisms and pathways, which are not necessarily interrelated. Therefore, it would be a great step forward for Alzheimer's disease therapy if a multifunctional nanotechnology approach could be developed for designing therapeutic cocktails that simultaneously and specifically target the main molecular culprits involved in AD. These molecular targets include (but are not limited to) A $\beta$ oligomers, ROS, excessive metal ions, tau phosphorylating kinases and cell cycle proteins.

Nevertheless, there are still many challenges regarding the biocompatibility of nanoparticles and nanodevices especially in a complex biological milieu like brain with a huge concentration of cells. Therefore, it seems that a long and puzzling path is ahead to make the envisioned nano-neurosurgical approaches of curing CNS diseases a practical technology and eventually a routine clinical practice [1, $11,47,90,91,92]$.

\section{Glossary}

\section{$\mathrm{Ab} \quad$ antibody}

AChEI acetylcholinesterase inhibitor

AD Alzheimer's disease

ADDL amyloid $\beta$-derived diffusible ligand

AgNP silver nanoparticle

aM attomolar $\left(10^{-18}\right.$ moles per liter $)$

amphipathic Pertains to a particle having two ends with different characteristics and long enough so that each end shows its own solubility effect.

Apo A-I Apolipoprotein A-I

APP A $\quad$ A precursor protein

$\mathrm{Au} \quad$ gold

AuNP gold nanoparticle

A $\beta \quad$ amyloid- $\beta$ peptide - A peptide generated from amyloid precursor protein, which is known in association with AD.

$A \beta_{42} \quad$ One of the two (the other is $A \beta_{40}$ ) more common isoforms of amyloid- $\beta$ protein

BBB blood brain barrier

$\mathrm{C}_{60} \mathrm{HyFn} \quad$ nanostructures of hydrated $\mathrm{C}_{60}$ fullerene 


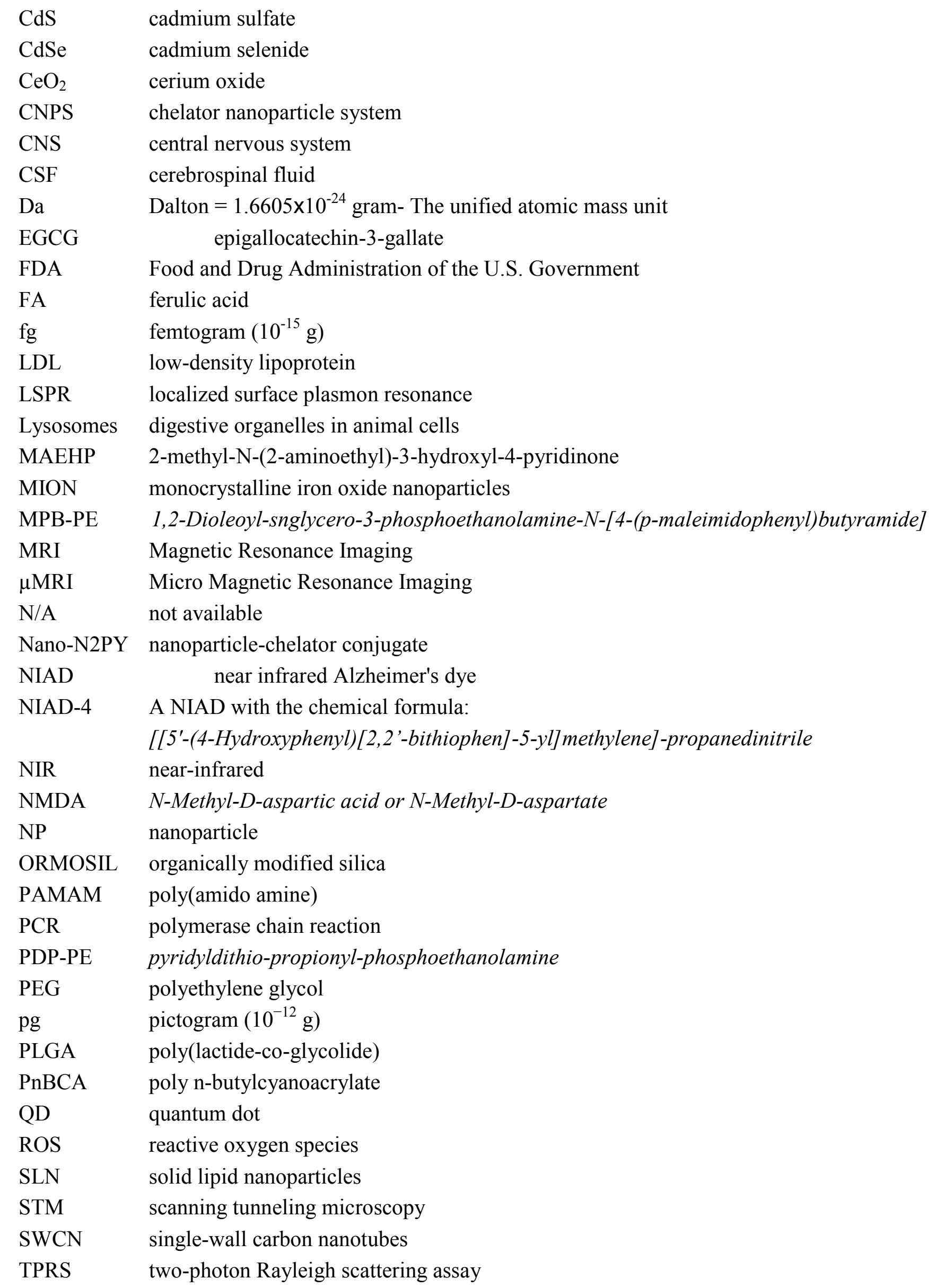




\section{References}

1. Nazem A, Mansoori GA. Nanotechnology solutions for Alzheimer's disease: advances in research tools, diagnostic methods and therapeutic agents. J Alzheimers Dis 2008; 13(2):199-223.

2. Alzheimer A. Ueber eine eigenartige Erkrankung der Himrinde. Allg Z Psychiat Med 1907; 64: 146-148.

3. Ferri CP, Prince M, Brayne C, Brodaty H, Fratiglioni L, Ganguli M, et al. Global prevalence of dementia: a Delphi consensus study. Lancet 2005 Dec 17; 366(9503):2112-7.

4. Sloane PD, Zimmerman S, Suchindran C, Reed P, Wang L, Boustani M, et al. The public health impact of Alzheimer's disease, 2000-2050: potential implication of treatment advances. Annu Rev Public Health 2002; 23:213-31.

5. Mortimer JA, Borenstein AR, Gosche KM, Snowdon DA. Very early detection of Alzheimer neuropathology and the role of brain reserve in modifying its clinical expression. $J$ Geriatr Psychiatry Neurol 2005 Dec; 18(4):218-23.

6. Nestor PJ, Scheltens P, Hodges JR. Advances in the early detection of Alzheimer's disease. Nat Med 2004 Jul; 10 Suppl:S34-S41.

7. Mucke L. Neuroscience: Alzheimer's Disease. Nature 2009; 461:895-7.

8. Murman DL, Colenda CC. The economic impact of neuropsychiatric symptoms in Alzheimer's disease: can drugs ease the burden? Pharmacoeconomics 2005; 23(3):227-42.

9. Uversky VN, Kabanov AV, Lyubchenko YL. Nanotools for megaproblems: probing protein misfolding diseases using nanomedicine modus operandi. J Proteome Res 2006 Oct; 5(10):250522.

10. Mansoori GA, Mohazzabi P, McCormack P, Jabbari S. Nanotechnology in cancer prevention, detection and treatment: bright future lies ahead. WRSTSD 2007; 4(2/3):226-57.

11. Singh S, Singh M, Gambhir IS. Nanotechnology for Alzheimer's disease detection. Digest Journal of Nanomaterials and Biostructures 2008; 3(2):75-9.

12. Mansoori GA. Principles of Nanotechnology: Molecular-Based Study of Condensed Matter in Small Systems. World Scientific Pub. Co.; 2005.

13. Mansoori GA. Principles of Nanotechnology (Molecular-Based Study of Condensed Matter in Small Systems), World Sci Pub Co, 2005.

14. Jain KK. The role of nanobiotechnology in drug discovery. Drug Discov Today 2005 Nov 1; 10(21):1435-42.

15. Modi G, Pillay V, Choonara YE. Advances in the treatment of neurodegenerative disorders employing nanotechnology. Annals of the New York Academy of Sciences 2010; 1184:154-72.

16. Mansoori GA, Brandenberg K, Shakeri-Zadeh A. Cancerous Cells Targeting and Folate-A Comparative Study of Two Folate-Conjugated Gold Nanoparticles for Cancer Nanotechnology Applications. Cancers 2010; 2[4], 1911-1928.

17. Georganopoulou DG, Chang L, Nam JM, Thaxton CS, Mufson EJ, Klein WL, et al. Nanoparticlebased detection in cerebral spinal fluid of a soluble pathogenic biomarker for Alzheimer's disease. Proc Natl Acad Sci U S A 2005; 102(7): 2273-2276.

18. Haes AJ, Chang L, Klein WL, Van Duyne RP. Detection of a biomarker for Alzheimer's disease from synthetic and clinical samples using a nanoscale optical biosensor. J Am Chem Soc 2005; 127(7): 2264-2271. 
19. Kang DY, Lee JH, Oh BK, Choi JW. Ultra-sensitive immunosensor for -amyloid (1-42) using scanning tunneling microscopy-based electrical detection. Biosens Bioelectron 2009; 24(5):14316.

20. Kang DY, Lee JH, Oh BK, Choi JW. Ultra-sensitive immunosensor for amyloid-beta (1-42) using scanning tunneling microscopy-based electrical detection. Biosensors and Bioelectronics 2009; 24(5):1431-6.

21. Neely A, Perry C, Varisli B, Singh AK, Arbneshi T, Senapati D, et al. Ultrasensitive and highly selective detection of Alzheimer's disease biomarker using two-photon Rayleigh scattering properties of gold nanoparticle. ACS Nano 2009; 3(9):2834-40.

22. Skaat H, Margel S. Synthesis of fluorescent-maghemite nanoparticles as multimodal imaging agents for amyloid-beta fibrils detection and removal by a magnetic field. Biochem Biophys Res Commun 2009; 386(4):645-9.

23. Hofmann-Amtenbrink M, Hofmann H, Montet X. Superparamagnetic nanoparticles - a tool for early diagnostics. Swiss Med Wkly 2010; 140(w13081).

24. Wadghiri YZ, Sigurdsson EM, Sadowski M, Elliott JI, Li Y, Scholtzova H, et al. Detection of Alzheimer's amyloid in transgenic mice using magnetic resonance microimaging. Magnetic Resonance in Medicine 2003; 50(2):293-302.

25. Yang J, Wadghiri YZ, Hoang DM, Tsui W, Sun Y, Chung E, et al. Detection of amyloid plaques targeted by USPIO-A-beta 1-42 in Alzheimer's disease transgenic mice using magnetic resonance microimaging. NeuroImage 2011; 55, 1600-1609.

26. Nesterov EE, Skoch J, Hyman BT, Klunk WE, Bacskai BJ, Swager TM. In Vivo Optical Imaging of Amyloid Aggregates in Brain: Design of Fluorescent Markers. Angew Chem Int Ed Engl 2005; $44[34], 5452-5456$.

27. Willets KA, Ostroverkhova O, He M, Twieg RJ, Moerner WE. Novel fluorophores for singlemolecule imaging. J Am Chem Soc 2003; 125[5], 1174-1175.

28. Jain KK. Nanotechnology in clinical laboratory diagnostics. Clin Chim Acta 2005; 358[1-2], 37 54.

29. Jaiswal JK, Mattoussi H, Mauro JM, Simon SM. Long-term multiple color imaging of live cells using quantum dot bioconjugates. Nat Biotechnol 2003; 21, 47-51.

30. Dubertret B, Skourides P, Norris DJ, Noireaux V, Brivanlou AH, Libchaber A. In vivo imaging of quantum dots encapsulated in phospholipid micelles. Science 2002; 298[5599], 1759-1762.

31. Zhang T, Stilwell JL, Gerion D, Ding L, Elboudwarej O, Cooke PA, et al. Cellular effect of high doses of silica-coated quantum dot profiled with high throughput gene expression analysis and high content cellomics measurements. Nano Lett. 2006; 6[4], 800-808.

32. Tokuraku K, Marquardt M, Ikezu T. Real-time imaging and quantification of amyloid-beta peptide aggregates by novel quantum-dot nanoprobes. PLoS One 2009; 4[12], e8492.

33. Xu G, Yong KT, Roy I, Mahajan SD, Ding H, Schwartz SA, et al. Bioconjugated quantum rods as targeted probes for efficient transmigration across an in vitro blood-brain barrier. Bioconjug Chem 2008; 19[6], 1179-1185.

34. Cummings JL. Defining and labeling disease-modifying treatments for Alzheimer's disease. Alzheimer's \& Dementia 2009; 5:406-18. 
35. Quist A, Doudevski I, Lin H, Azimova R, Ng D, Frangione B, et al. Amyloid ion channels: a common structural link for protein-misfolding disease. Proc Natl Acad Sci U S A 2005 Jul 26; 102(30):10427-32.

36. Rhee SK, Quist AP, Lal R. Amyloid beta protein-(1-42) forms calcium-permeable, Zn2+-sensitive channel. J Biol Chem 1998 May 29; 273(22):13379-82.

37. Butterfield DA, Boyd-Kimball D. The critical role of methionine 35 in Alzheimer's amyloid ?peptide (1-42)-induced oxidative stress and neurotoxicity. Biochim Biophys Acta Proteins Proteomics 2005; 1703(2):149-56.

38. Mattson MP. Pathways towards and away from Alzheimer's disease. Nature 2004 Aug 5; 430(7000):631-9.

39. Ikeda K, Okada T, Sawada S, Akiyoshi K, Matsuzaki K. Inhibition of the formation of amyloid beta-protein fibrils using biocompatible nanogels as artificial chaperones. FEBS Lett 2008; 580[28-29], 6587-6595.

40 Boridy S, Takahashi H, Akiyoshi K, Maysinger D. The binding of pullulan modified cholesteryl nanogels to Ab oligomers and their suppression of cytotoxicity. Biomaterials 2009; 30[29], 55835591.

41. Dugan LL, Lovett EG, Quick KL, Lotharius J, Lin TT, O'Malley KL. Fullerene-based Antioxidants and neurodegenerative disorders. Parkinsonism Relat Disord 2001 Jul; 7(3):243-6.

42. Dugan LL, Turetsky DM, Du C, Lobner D, Wheeler M, Almli CR, et al. Carboxyfullerenes as neuroprotective agents. Proc Natl Acad Sci U S A 1997 Aug 19; 94(17):9434-9.

43. Podolski IY, Podlubnaya ZA, Kosenko EA, Mugantseva EA, Makarova EG, Marsagishvili LG, et al. Effects of hydrated forms of C60 fullerene on amyloid 1-peptide fibrillization in vitro and performance of the cognitive task. J Nanosci Nanotechnol 2007 Apr; 7(4-5):1479-85.

44. Dugan LL, Gabrielsen JK, Yu SP, Lin TS, Choi DW. Buckminsterfullerenol free radical scavengers reduce excitotoxic and apoptotic death of cultured cortical neurons. Neurobiol Dis 1996 Apr; 3(2):129-35.

45. Huang $\mathrm{H}, \mathrm{Ou} \mathrm{H}$, Hsieh S, Chiang L. Blockage of amyloid beta peptide-induced cytosolic free calcium by fullerenol-1, carboxylate C60 in PC12 cells. Life Sci 2000; 66[16], 1525-1533.

46. D'Angelo B, Santucci S, Benedetti E, Di Loreto S, Phani RA, Falone S, et al. Cerium oxide nanoparticles trigger neuronal survival in a human Alzheimer disease model by modulating BDNF pathway. Curr Nanosci 2009; 5(2):167-76.

47. Suh WH, Suslick KS, Stucky GD, Suh YH. Nanotechnology, nanotoxicology, and neuroscience. Prog Neurobiol 2009; 87(3):133-70.

48. Mansoori GA, George TF, Assoufid L, Zhang G. Molecular Building Blocks for Nanotechnology, Springer, New York. 2007.

49. Nikakhtar A, Nasehzadeh A, Mansoori GA.Formation and Stability Conditions of DNADendrimer Nano-Clusters. J Comp'l \& Theor'l Nanoscience 2007 May; 4(3): 521-528 (8).

50. Klajnert B, Cortijo-Arellano M, Cladera J, Bryszewska M. Influence of dendrimer's structure on its activity against amyloid fibril formation. Biochem Biophys Res Commun 2006 Jun 23; 345(1):21-8.

51. Patel D, Henry J, Good T. Attenuation of beta-amyloid induced toxicity by sialic acid-conjugated dendrimeric polymers. Biochim Biophys Acta 2006 Dec; 1760(12):1802-9. 
52. Kogan MJ, Bastus NG, Amigo R, Grillo-Bosch D, Araya E, Turiel A, et al. Nanoparticlemediated local and remote manipulation of protein aggregation. Nano Lett 2006 Jan; 6(1):110-5.

53. Mansoori GA. Diamondoid Molecules. Advances in Chemical Physics. 2007. p. 207-58.

54. Reisberg B, Doody R, Stoffler A, Schmitt F, Ferris S, Mobius HJ. Memantine in moderate-tosevere Alzheimer's disease. N Engl J Med 2003 Apr; 348(14):1333-41.

55. Lipton SA. Paradigm shift in NMDA receptor antagonist drug development: molecular mechanism of uncompetitive inhibition by memantine in the treatment of Alzheimer's disease and other neurologic disorders. J Alzheimers Dis 2004 Dec; 6(6 Suppl):S61-S74.

56. Rawat M, Singh D, Saraf S, Saraf S. Nanocarriers: promising vehicle for bioactive drugs. Biol Pharm Bull 2006; 29(9):1790-80.

57. Wang J, Valmikinathan CM, Yu X. Nanostructures for bypassing blood brain barrier. Current Bioactive Compounds 2009; 5(3):195-205.

58. Blasi P, Giovagnoli S, Schoubben A, Ricci M, Rossi C. Solid lipid nanoparticles for targeted brain drug delivery. Adv Drug Deliv Rev 2007; 59(6):454-77.

59. Yang F, Lim GP, Begum AN, Ubeda OJ, Simmons MR, Ambegaokar SS, et al. Curcumin inhibits formation of amyloid beta oligomers and fibrils, binds plaques, and reduces amyloid in vivo. $J$ Biol Chem 2005; 280[7], 5892-5901.

60. Mulik RS, Monkkonen J, Juvonen RO, Mahadik KR, Paradkar AR. ApoE3 mediated poly(butyl) cyanoacrylate nanoparticles containing curcumin: study of enhanced activity of curcumin against beta amyloid induced cytotoxicity using in vitro cell culture model. Mol Pharm 2010; 7[3], 815825 .

61. Brambilla D, Le Droumaguet B, Nicolas J, Hashemi SH, Wu L-P, Moghimi SM, et al. Nanotechnologies for Alzheimer's disease: diagnosis, therapy, and safety issues. Nanomedicine: 2011 Oct; 7(5):521-40.

62. Wilson B, Samanta MK, Santhi K, Kumar KP, Paramakrishnan N, Suresh B. Poly(nbutylcyanoacrylate) nanoparticles coated withpolysorbate 80 for the targeted delivery of rivastigmine into the brainto treat Alzheimer's disease. Brain Res 2008; 1200:159-68 1200[159], 168.

63. Yang Z, Zhang Y, Yang Y, Sun L, Han D, Li H, et al. Pharmacological and toxicological target organelles and safe use of single-walled carbon nanotubes as drug carriers in treating Alzheimer disease. Nanomedicine 2010; 6(3):427-41.

64. Pike CJ, Carroll JC, Rosario ER, Barron AM. Protective actions of sex steroid hormones in Alzheimer's disease. Front Neuroendocrinol 2009; 30(2):239-58.

65. Sahni JK, Doggui S, Ali J, Baboota S, Dao L, Ramassamy C. Neurotherapeutic applications of nanoparticles in Alzheimer's disease. Journal of Controlled Release 2011; 152(2):208-31.

66. Wang X, Chi N, Tang X. Preparation of estradiol chitosan nanoparticles for improving nasal absorption and brain targeting. Eur J Pharm Biopharm 2008; 70(3):735-40.

67. He W, Horn SW, Hussain MD. Improved bioavailability of orally administered mifepristone from PLGA nanoparticles. Int J Pharm 2007; 334:173-8.

68. Belanoff JK, Jurik J, Schatzberg LD, DeBattista C, Schatzberg AF. Slowing the progression of cognitive decline in Alzheimer's disease using mifepristone. J Mol Neurosci 2002; 19:201-6. 
69. Rezai-Zadeh K, Arendash GW, Hou H, Fernandez F, Jensen M, Runfeldt M, et al. Green tea epigallocatechin-3-gallate (EGCG) reduces beta-amyloid mediated cognitive impairment and modulates tau pathology in Alzheimer transgenic mice. Brain Res 2008; 1214:177-87.

70. Zhang YW, Xu H. Molecular and cellular mechanisms for Alzheimer's disease: Understanding APP metabolism. Curr Mol Med 2007; 7(7):687-96.

71. Smith A, Giunta B, Bickford PC, Fountain M, Tan J, Shytle RD. Nanolipidic particles improve the bioavailability and alpha-secretase inducing ability of epigallocatechin-3-gallate (EGCG) for the treatment of Alzheimer's disease. Int J Pharm 2010; 389(1-2):207-12.

72. Bush AI. Drug development based on the metals hypothesis of Alzheimer's disease. J Alzheimer's Dis 2008; 15(2):223-40.

73. Castellani RJ, Moreira PI, Liu G, Dobson J, Perry G, Smith MA, et al. Iron: the Redox-active center of oxidative stress in Alzheimer disease. Neurochem Res 2007 Oct; 32(10):1640-5.

74. Smith MA. Oxidative stress and iron imbalance in Alzheimer disease: how rust became the fuss! $J$ Alzheimers Dis 2006; 9(3 Suppl):305-8.

75. Huang X, Moir RD, Tanzi RE, Bush AI, Rogers JT. Redox-active metals, oxidative stress, and Alzheimer's disease pathology. Annals New York Acad. Sci 2004: 1012, 153-163.

76. Curtain C, Ali F, Volitakis I, Cherny R, Norton R, Beyreuther K, et al. Alzheimer's disease amyloid- binds $\mathrm{Cu}$ and $\mathrm{Zn}$ to generate an allosterically-ordered membrane-penetrating structure containing SOD-like subunits. J Biol Chem 2001; 276:20466-73.

77. Huang X, Cuajungco MP, Atwood CS, Hartshorn MA, Tyndall J, Hanson GR, et al. Cu(II) potentiation of Alzheimer Abeta neurotoxicity: correlation with cell-free hydrogen peroxide production and metal reduction. J Biol Chem 1999; 274:37111-6.

78. Liu G, Men P, Perry G, Smith MA. Metal chelators coupled with nanoparticles as potential therapeutic agents for alzheimer's disease. Journal of Nanoneuroscience 2009; 1(1):42-55.

79. Liu G, Men P, Harris PL, Rolston RK, Perry G, Smith MA. Nanoparticle iron chelators: a new therapeutic approach in Alzheimer disease and other neurologic disorders associated with trace metal imbalance. Neurosci Lett 2006 Oct 9; 406(3):189-93.

80. Liu G, Garrett MR, Men P, Zhu X, Perry G, Smith MA. Nanoparticle and other metal chelation therapeutics in Alzheimer disease. Biochim Biophys Acta 2005 Sep 25; 1741(3):246-52.

81. Liu G, Men P, Kudo W, Perry G, Smith MA. Nanoparticle-chelator conjugates as inhibitors of amyloid- $\hat{I}^{2}$ aggregation and neurotoxicity: A novel therapeutic approach for Alzheimer disease. Neurosci Lett 2009; 455(3):187-90.

82. Cui Z, Lockman PR, Atwood CS, Hsu CH, Gupte A, Allen DD, et al. Novel D-penicillamine carrying nanoparticles for metal chelation therapy in Alzheimer's and other CNS diseases. Eur $J$ Pharm Biopharm 2005 Feb; 59(2):263-72.

83. Picone P, Bondi ML, Montana G, Bruno A, Pitarresi G, Giammona G, et al. Ferulic acid inhibits oxidative stress and cell death induced by $\mathrm{Ab}$ oligomers: Improved delivery by solid lipid nanoparticles. Free Radical Research 2009; 43(11):1133-45.

84. Bondi ML, Montana G, Craparo EF, Picone P, Capuano G, Di Carlo M, et al. Ferulic acid-loaded lipid nanostructures as drug delivery systems for Alzheimer's disease: Preparation, characterization and cytotoxicity studies. Curr Nanosci 2009; 5(1):26-32. 
85. Roy I, Stachowiak MK, Bergey EJ. Nonviral gene transfection nanoparticles: function and applications in the brain. Nanomedicine: Nanotechnology, Biology, and Medicine 2008; 4(2):8997.

86. Nikakhtar A, Nasehzadeh A, Mansoori GA. Formation and Stability Conditions of DNADendrimer Nano-Clusters. Journal of Computational and Theoretical Nanoscience 2007; 4(3):521-8.

87. Nikakhtar A, Nasehzadeh A, Mansoori GA. DNA-dendrimer nano-cluster electrostatics prediction with the non-linear Poission-Boltzman equation. J Comput'l \& Theor'l Nanoscience 2005; 2(3):378-84.

88. Boussif O, LezoualC'H F, Zanta MA, Mergny MD, Scherman D, Demeneix B, et al. A versatile vector for gene and oligonucleotide transfer into cells in culture and in vivo: Polyethylenimine. Proc NatlAcad Sci U SA 1995; 92(16):7297-301.

89. Bharali DJ, Klejbor I, Stachowiak EK, Dutta P, Roy I, Kaur N, et al. Organically modified silica nanoparticles: A nonviral vector for in vivo gene delivery and expression in the brain. Proc Natl Acad Sci U S A 2005; 102(32):11539-44.

90. Silva GA. Neuroscience nanotechnology: progress, opportunities and challenges. Nat Rev Neurosci 2006; 7(1):65-74.

91. Lynch Z. The future of neurotechnology innovation. Epilepsy Behav 2009; 15(2):120-2.

92. Ellis-Behnke RG, Teather LA, Schneider GE, So KF. Using Nanotechnology to Design Potential Therapies for CNS Regeneration. Current Pharmaceutical Design 2007; 13:2519-28.

(C) 2011 by the authors; licensee Insciences Journal.

Open Access article under the terms and conditions of Creative Commons Attribution Non-Commercial License 3.0 Unported. 